\title{
AN UNUSUAL COMPLICATION OF TOTAL KNEE REPLACEMENT
}

\author{
A CASE REPORT
}

TIMOTHY G. McWILLIAMS, CHOONG L. POON, CHARLES N. McCOLLUM

From South Manchester University Hospital Trust, Manchester, England

After total knee replacement a 57-year-old woman developed increasing pain in her left calf on exercise. This was due to erosion of the popliteal artery by a spur of cement. Removal of the spur with resection and Dacron grafting of the damaged section of the vessel cured her symptoms.

J Bone Joint Surg [Br] 1997;79-B:102-3.

Received 12 July 1996; Accepted 28 August 1996

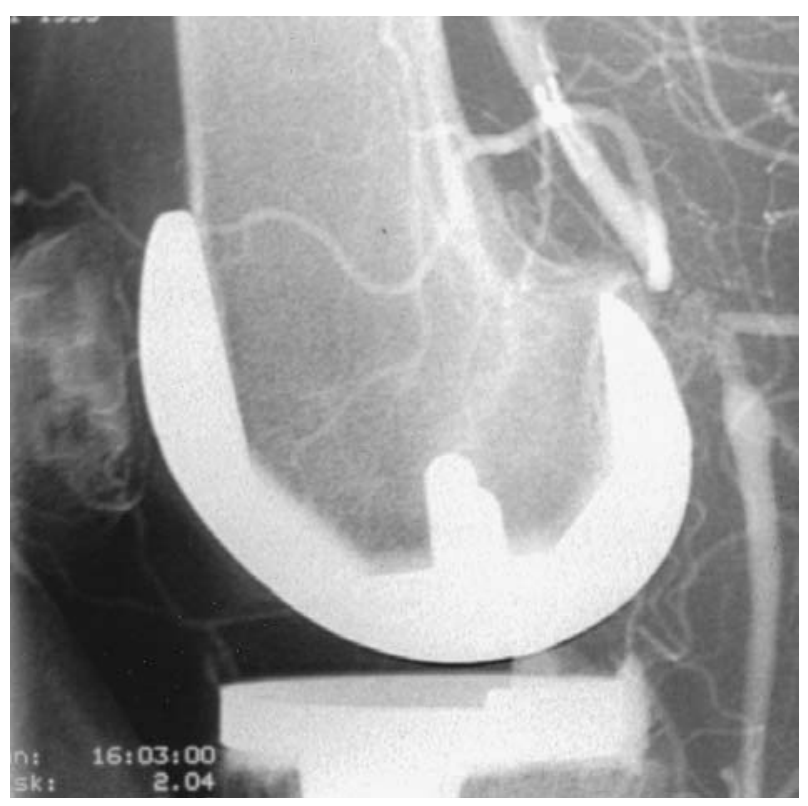

Fig. 1a
Vascular complications are rare after total knee arthroplasty. ${ }^{1}$ Acute damage may result from disruptive forces applied to calcified atherosclerotic vessels by the pneumatic tourniquet or during intraoperative manipulation. Chronic injury may be similar to that seen in the popliteal entrapment syndrome ${ }^{2}$ for which several classification systems have been proposed. ${ }^{3}$ The simplest system distinguishes abnormalities of the artery (type I) from those of the

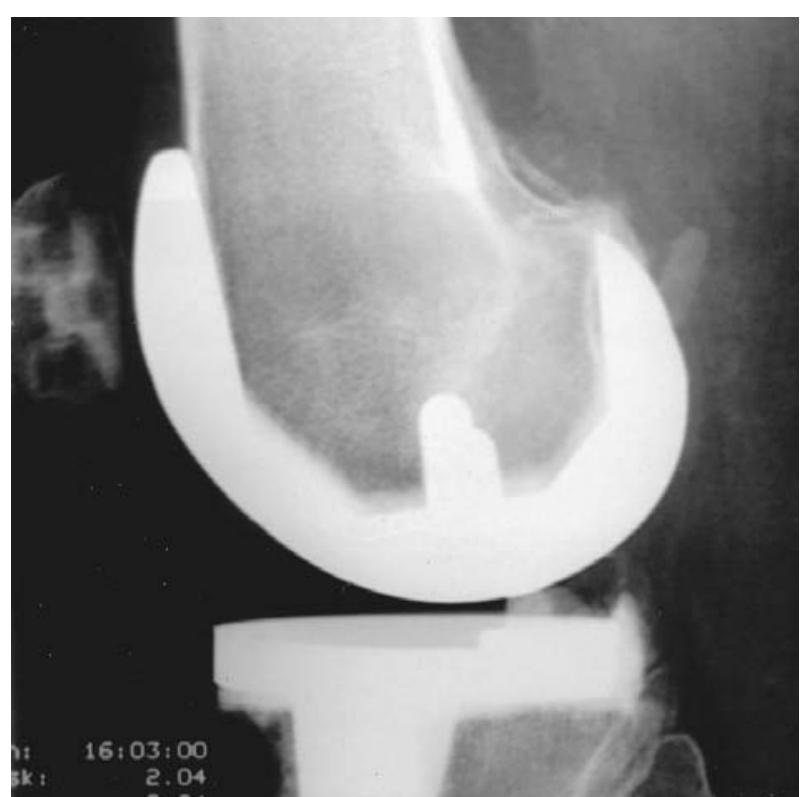

Fig. 1b

Angiograph showing localised occlusion of the mid-popliteal artery (a) and a radiograph showing a posterior opacity (b).

T. G. McWilliams, BSc, MB BS, Senior House Officer in Vascular Surgery

C. L. Poon, BSc, MB ChB, MRCP, FRCR, Senior Registrar in Radiology

C. N. McCollum, MD, FRCS, Professor of Surgery

South Manchester University Hospital Trust, Withington Hospital, Nell Lane, West Didsbury, Manchester M20 8LR, UK.

Correspondence should be sent to Professor C. N. McCollum.

(c)1997 British Editorial Society of Bone and Joint Surgery 0301-620X/97/17083\$2.00 surrounding musculotendinous structures (type II). We present a novel cause of chronic ischaemia.

\section{CASE REPORT}

A 57-year-old woman had increasing pain in her left calf on exercise, which had been present for two years since undergoing bilateral knee replacement. The pain was 


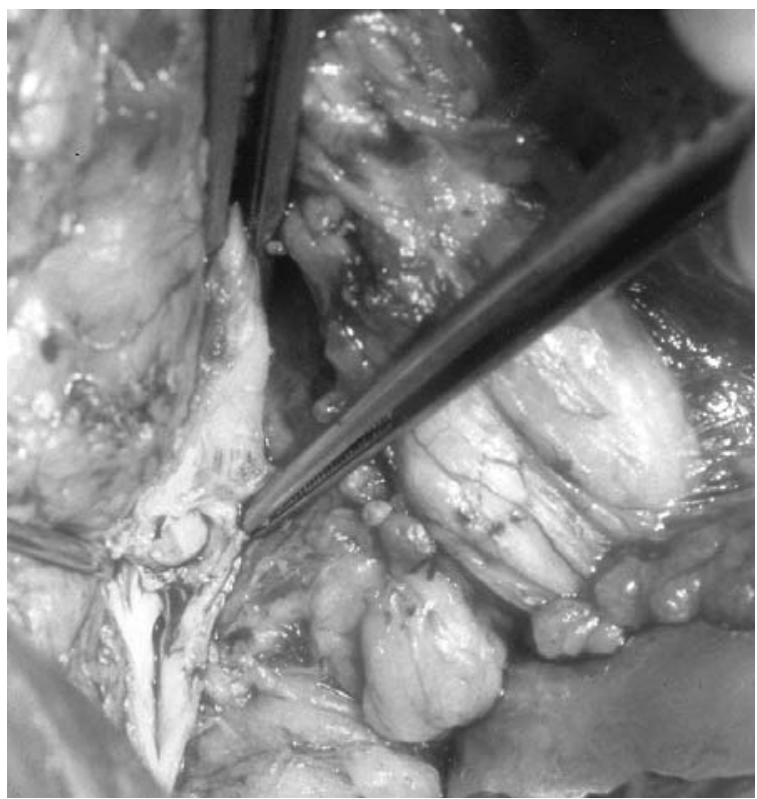

Fig. 2

At operation; left popliteal arteriotomy showing intravascular cement.

'explosive' in character and occurred on minimal exertion. When present at night, it was relieved by standing. Since the operation her left foot had never been as warm as the other side. There was no history of diabetes, ischaemic heart disease or cerebrovascular problems, and there had been no symptoms of peripheral vascular dysfunction before the knee replacements. The patient was taking thyroxine for hypothyroidism and a beta-blocking agent for hypertension. She had previously had a lumbar laminect- omy for nerve-root compression, but had never smoked.

The patient weighed $115 \mathrm{~kg}$, and was in sinus rhythm, with no abnormalities of the chest or abdomen. Both legs were well perfused but there were no palpable pulses below the femoral on the left: Doppler assessment confirmed damping of the arterial signals at the left ankle. Both knees had free movement from $5^{\circ}$ to $110^{\circ}$ flexion and were well aligned. Colourflow duplex scanning showed occlusion of the left popliteal artery for $3 \mathrm{~cm}$ with monophasic signals distally. The ankle brachial pressure index (ABPI) was 0.56 at rest and the pulse was undetectable on the left on exercise. Peripheral angiography confirmed severe localised stenosis of the left popliteal artery with poststenotic dilatation (Fig. 1a) which was related to a radio-opaque projection arising from the posterior aspect of the femoral component of her TKR (Fig. 1b). The rest of the peripheral arterial system was normal.

At operation a spur of cement from the intercondylar area was eroding the anterior aspect of the popliteal artery (Fig. 2), causing chronic endovascular arterial occlusion. The spur was removed and the affected segment of the popliteal artery replaced by a $6 \mathrm{~mm}$ Dacron graft. After operation the ABPI was $>1$ on both sides. Eight months later, the patient was free of pain and her increased mobility was allowing her to lose weight.

No benefits in any form have been received or will be received from a commercial party related directly or indirectly to the subject of this article.

\section{REFERENCES}

1. Rand JA. Vascular complications of total knee arthroplasty: report of three cases. J Arthroplasty 1987;2:89-93.

2. McAuley CE, Steed DL, Webster MW. Arterial complications of total knee replacement. Arch Surg 1984;119:960-2.

3. MacSweeney S. Popliteal artery entrapment syndrome. Surgery (Oxford) 1994;12:11:245-6. 